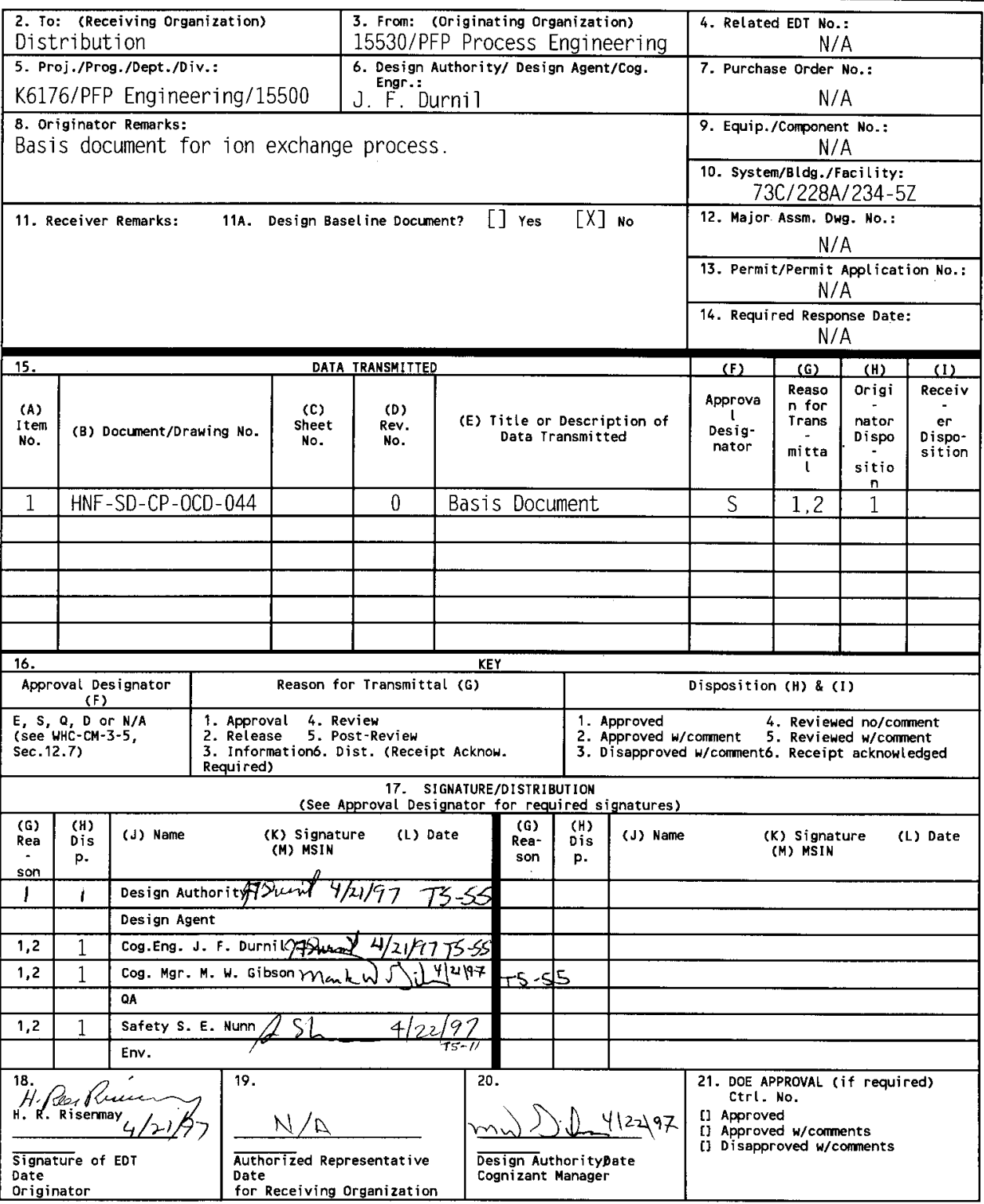

BD-7400-172-2 (05/96) GEF097 


\section{BASIS DOCUMENT FOR PFP PLUTONIUM NITRATE ION EXCHANGE PROCESS IN ROOM $228 \mathrm{~A}$}

H. Rees Risenmay

B\&W Hanford Co., Richland, WA 99352

U.S. Department of Energy Contract DE-AC06-96RL13200

EDT/ECN: $617748 \quad$ UC: 711

Org Code: $15530 \quad$ Charge Code: K6176

B\&R Code: EW7040000 Total Pages: 9

Key Words: Ion Exchange Column. Anion Exchange Resin. Plutonium, Nitrate

Abstract: An ion exchange process wi 11 be installed in glovebox HC- 7 in room 228A/234-5Z to remove impurities from Plutonium Nitrate solutions that would interfere with the Operation of the Vertical Denitration Calciner.

Reillex is a registered trademark of Reilly Industries Inc., Indianapolis, IN.

IRADEMARK DISCLAIMER. Reference herein to any specific comercial product, process, or service by trade name, trademark, manufacturer, or otherwise, does not necessarily constitute or imply its endorsement, recommendation, or favoring by the United States Government or any agency thereof or $i$ ts contractors or subcontractors.

Printed in the United States of America. To obtain copies of this document, contact: Document Control Services, P.0. 80x 950, Mailstop H6-08, Richland WA 99352, Phone (509) 372-2420; Fax (509) 376-4989.
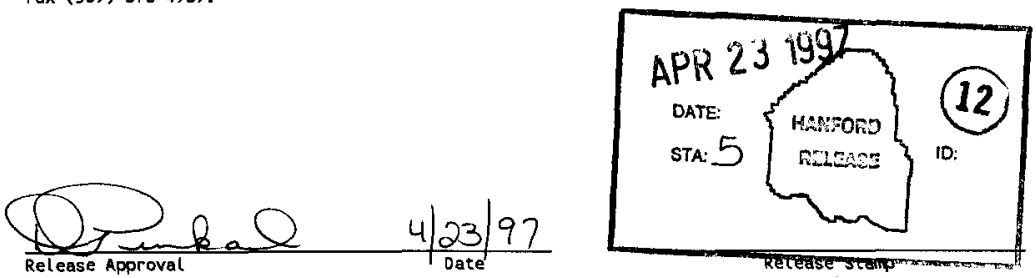

\section{Approved for Public Release}


Basis Document for PFP Plutonium Nitrate Ion Exchange Process in Room 228A

Prepared by:

H. Rees Risenmay Senior Engineer

PFP Process Engineering 


\section{TABLE OF CONTENTS}

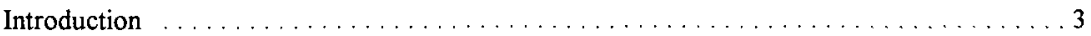

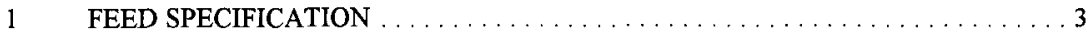

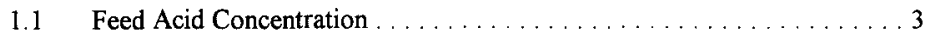

1.2 Cycle Plutonium Loading $\ldots \ldots \ldots \ldots \ldots \ldots \ldots$

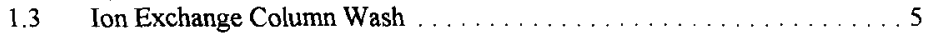

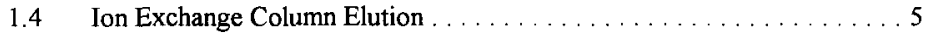

2 PRODUCT SPECIFICATION $\ldots \ldots \ldots \ldots \ldots \ldots \ldots \ldots \ldots \ldots \ldots \ldots$

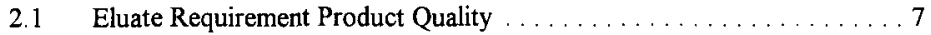

3 ION EXCHANGE COLUMN OVER-PRESSURIZATION $\ldots \ldots \ldots \ldots \ldots \ldots \ldots$

3.1 Ion Exchange Column Pressure $\ldots \ldots \ldots \ldots \ldots \ldots$

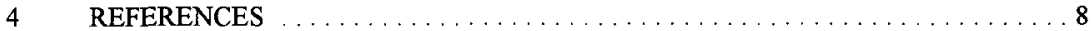


Introduction:

The PFP facility currently has approximately 4300 liters of plutonium nitrate solution in storage. This material will be calcined by the Vertical Denitration Calciner (VDC) located in room 230C. However, part of the material needs to be purified to remove constituents that will interfere with the calcination process. An Ion Exchange process using Reillex ${ }^{\mathrm{TM}}$ $\mathrm{HPQ}^{\mathrm{a}}$ anion exchange resin was tested by the Plutonium Process Support Laboratories (PPSL) (1). The Ion exchange process is to be installed in glovebox HC-7 in room $228 \mathrm{~A} / 234-5 \mathrm{Z}$. The plutonium separated from the interfering constituents will be in a concentrated condition ready to be calcined by the VDC in room $230 \mathrm{C}$. The oxide product of the VDC will be placed into the $2736-Z$ vaults for long term storage

The VDC calcination process is not covered by this basis document.

The following specifications set the limits necessary for protection of personnel, environmental safety, minimizing equipment damage, product quality, and maintaining process efficiency.

\section{FEED SPECIFICATIONS}

\subsection{Feed Acid Concentration}

Limit:

Variable

$\mathrm{H}^{+}$ion concentration
Specification Limit

7 to $8 \mathrm{M}$

Basis: (Efficiency, Safety)

Laboratory testing (1) of anion exchange resins have shown that the maximum resin loading is accomplished at about the 7 to $8 \mathrm{M}$ nitrate ion concentration. No other source of acid of any consequence will be found in the feed solutions, therefore, the acid concentration will be used to ensure that the nitrate ion concentration is in the correct range. All feed to the ion exchange column (RMC filtrate, PRF Wash, and PUREX plutonium nitrate solutions) will have nitric acid concentration adjusted to be compatible with the ion exchange resin used (Reillex ${ }^{\mathrm{TM}} \mathrm{HPQ}^{\mathrm{a}}$ anion exchange resin)

Ion exchange resins used in the past for Pu purification are organic material that are very suseptable to degradation by nitric acid. Under extreme conditions of high nitric acid concentrations and high plutonium nitrate loading of the ion exchange resin the stability of the ion exchange column can be jeopardized if the 
temperature is allowed to rise to the ignition point of the resin. This problem led to the accident at the $233 \mathrm{~S}$ building at the REDOX facility(2). Another accident was at PFP in $242 Z$ caused by long term exposure of the ion exchange resin in the column to nitric acid in conjunction with high loading of the ion exchange resins which resulted in the explosion of the ion exchange column with resultant personnel injury.

The Reillex ${ }^{\mathrm{TM}} \mathrm{HPQ}^{\mathrm{a}}$ anion exchange resin has been shown to be much more stable and resistant to degradation by the nitric acid and radiological attack by the material being loaded on the resin than the former resins commonly used to purify plutonium. It has been subjected to boiling concentrated nitric acid for long periods with negligible damage(3). Engineering evaluation and laboratory testing have been done to define acceptable plutonium feed solutions.

\subsection{Cycle Plutonium Loading}

Limit

Variable $\quad$ Specification Limit

Plutonium Loading $\quad<1600$ grams Pu per cycle.

Basis: (Efficiency)

The Reillex ${ }^{\mathrm{TM}} \mathrm{HPQ}^{\mathrm{a}}$ anion exchange resin process was shown in PPSL tests to load about 70 to 90 grams of plutonium per liter of resin (1). The ion exchange column has a volume of about 33 liters of resin.

70 grams $/$ liter $\times 33$ liters $=2310$ grams

90 grams/liter $\times 33$ liters $=2970$ grams

The capacity of the IX column is in the range of 2.3 to $3.0 \mathrm{~kg}$. The 1600 grams of plutonium is well within the capacity range of the resin. A margin under the $2.3 \mathrm{~kg}$ limit is desirable to prevent $\mathrm{Pu}$ loss to the raffinate. Excess $\mathrm{Pu}$ in the raffinate requires recycle or adds unnecessarily to the tank farm Pu loading. With operation experience the loading per cycle may be increased as directed by Process Engineering to increase operation efficiency. 


\subsection{Ion Exchange Column Wash}

Limit:

Variable

Wash Volume

Basis: (Efficiency)

\section{Specification Limit}

$<40 \mathrm{~L}$

The 40 liters of wash effectively moves the residual feed column volume (about 33 liters) out of the resin bed. Other plutonium ion exchange processes used at other sites use larger wash volumes to achieve greater purity of the plutonium which is not necessary for successful VDC operation at PFP.

Limit

Variable

Specification Limit

Nitric acid concentration $\quad 7.5+/-.5 \mathrm{M}$

Basis: (Efficiency)

7.5 M Nitric Acid is used to wash the column to ensure that the plutonium remains on the column while the impurities from the feed are flushed on through the column.

\subsection{Ion Exchange Column Elution}

Limit:

Variable

$\mathrm{H}^{+}$ion concentration

Basis: (Efficiency)
Specification Limit

$0.4-0.5 \mathrm{M}$ nitric acid will be used to elute IX column

$0.5 \mathrm{M}$ Nitric Acid will reduce the concentration of nitrate ions in solution to the level that the Plutonium ions will no longer be able to form the hexanitrato complex of $\mathrm{Pu}\left(\mathrm{NO}_{3}\right)_{6}^{-2}$ which is required for the plutonium to be adsorbed on an anion exchange resin. The cation $\mathrm{Pu}^{+4}$ is rejected from the resin as the elution fluid strips away the nitrate ions present in the hexanitrato complex which leaves the resin loaded with nitrate ions instead of the hexanitrato complex. 
Limit:

Variable

Elution Volume

\section{Specification Limit}

83 liters

Basis: (Efficiency)

Laboratory testing has determined that column eluate volume of about 2.5 bed volumes are required to elute 95 percent of the plutonium nitrate loaded on the column.

0.5 bed volumes $\mathrm{x} 33$ liters $/$ bed volume $=\sim 17$ liters

2.0 bed volumes $\times 33$ liters/bed volume $=66$ liters

To increase product concentration with operation experience as a guide, about the first 0.5 bed volume displaced by the elution process will be collected with the wash for recycle to the IX column. To increase product concentration the elution process will be discontinued after 83 liters before the concentration in the eluate tails off. An example of the effect on Pu product concentration follows:

3 bed volumes $\mathrm{x} 33$ liters/bed volume $=\sim 100$ liters

$0.98 \times 1600$ grams $\mathrm{Pu} / 100$ liters $=\sim 15$ grams $\mathrm{Pu} /$ liter product

0.5 bed volumes to recycle $\times 33$ liters $/$ bed volume $=\sim 17$ liters

2 bed volumes product eluate collected $x 33$ liters $=\sim 66$ liters

Stopping elution at 2.5 bed volumes leaves $\sim 5 \%$ of $\mathrm{Pu}$ on IX column.

$0.95 \times 1600$ grams $\mathrm{Pu} / 66$ liters $=\sim 23$ grams $\mathrm{Pu} /$ liter product

Limit:

Variable

Specification Limit

ERAT heel

$7.5+/ .0 .5$ liters of $12 \mathrm{M}$ nitric acid

Basis: (Criticality Specification)

Eluant Receipt and Adjustment Tank (ERAT) will be pre-loaded with $12 \mathrm{M}$ nitric acid to bring the nitric acid concentration of the 66 liters of Eluate to $\sim 1.6$ Molar. 
66 liters of eluate at $0.5 \mathrm{M}=33$ moles of nitric acid.

1.6 moles $/$ liter $\times 66$ liters $=105.6$ moles of nitric acid.

$105.6-33=72.6$ moles additional acid required .

$1.6 \mathrm{moles} /$ liter $(66+\mathrm{x})$ liters $=0.5 \mathrm{moles} / \mathrm{liter}(66$ liters $)+12 \mathrm{moles} / \mathrm{liter}(\mathrm{x}$ liters $)$

$\mathrm{x}=(105.6-33) /(12-1.6)=6.98$ liters $12 \mathrm{M}$ nitric acid heel

The final nitric acid concentration of $1.6 \mathrm{M}$ is high enough to have a cushion above the Criticality Specifation minimum concentration of $1.3 \mathrm{M}$ (required to prevent $\mathrm{Pu}$ polymer formation) but will minimize the extra acid that the VDC off gas scrubber will be required to neutralize.

\section{PRODUCT SPECIFICATIONS}

2.1 Eluate Requirement Product Quality

Limit:

Variable

Specification Limit

$\mathrm{H}^{+}$ion concentration

$\sim 1.6 \mathrm{M}$ nitric acid.

Basis: (Criticality Specifications, Efficiency)

The eluate will be loaded into the ERAT with a fresh 12M nitric acid heel to yield a solution with about $1.6 \mathrm{M}$ nitric acid concentration to meet criticallity specifications requiring 1.3 M nitric acid concentraion. Efficient operation of the vertical calciner is facilitated by holding the nitric acid concentration down to minimize the acidic off gas needing neutralization in the scrubber. 
BASIS DOCUMENT

HFN-SD-CP-OCD-044 REV. 0

PAGE 8

3 ION EXCHANGE COLUMN OVER-PRESSURIZATION

\subsection{Ion Exchange Column Pressure}

Limit:

\begin{tabular}{ll}
\multicolumn{1}{c}{ Variable } & Specification Limit \\
Ion Exchange Column Pressure & $\leq 40 \mathrm{psig}$ \\
Basis: (Safety) &
\end{tabular}

Rupture disks are installed at the top and the bottom of the ion exchange column. Each disk is set to rupture automatically when 40 psig is reached within the column. The rupture disks allow for the safe depressurization of the column in the event of resin gassing, column plugging, or mechanical equipment failure occurs. The rupture disks will release the pressurized gasses, liquids and resin on to the glovebox floor and prevent the ion exchange column from rupturing and causing any containment damage.

4 References

1 Sutter, C. S., Internal Letter \#15FOO-96-032, "Summary Reports of the Solution Stabilization Testing Preformed In Support of 94-1 Program Activities", Attachment 4, April 1996

2 Barghusen, J. and A.A. Jonke, "Safety in Chemical Processing", Reactor Fuel Processing, Vol. 7, No. 4, Fall 1964, pages 297-303.

3 Marsh, S. F., "Evaluation of a New, Macroporous Polyvinylpyridine Resin for Processing Plutonium Using Nitrate Anion Exchange," Los Alamos National laboratory report LA-1 1490 (April 1989)

4 Marsh, S. F., "The Effects of IN-Situ Alpha-Particle Irradiations on Six Strong-Base Anion Exchange Resin," Los Alamos National laboratory report LA-12055 (April 1991).

5 Reilly Industries Inc., Technical Information, Reillex ${ }^{\mathrm{TM}} \mathrm{HPQ}$, Indianapolis IN 


\section{DISTRIBUTION SHEET}

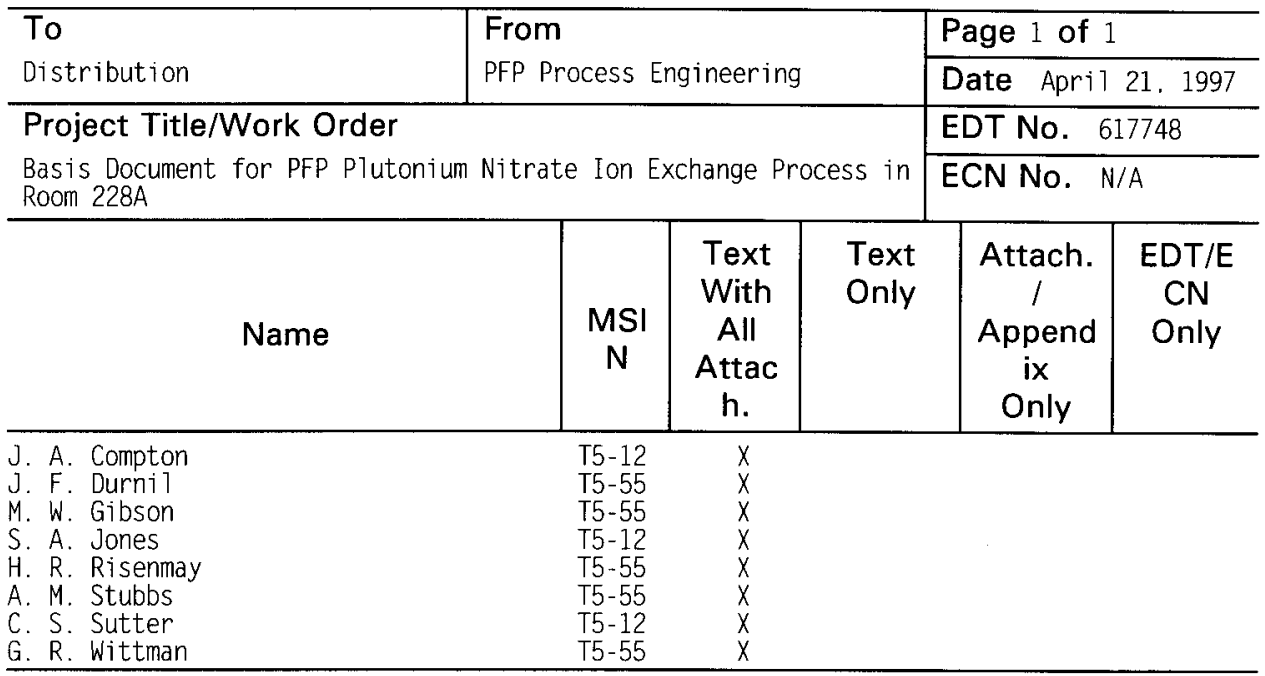

